\title{
Self-consistent field theoretic simulations of amphiphilic triblock copolymer solutions: Polymer concentration and chain length effects
}

\author{
X.-G. Han 112$] ;,$ Y.-H. Ma $a^{112}$ \\ ${ }^{1}$ Inner Mongolia Key Laboratory for Utilization of Bayan Obo Multi-Metallic Resources: \\ Elected State Key Laboratory, Inmongolia Science and Technology University, Baotou 014010, China \\ 2 School of Mathematics, Physics and Biology, Inmongolia Science and Technology University, \\ Baotou 014010, China
}

Received December 18, 2013, in final form March 28, 2014

\begin{abstract}
Using the self-consistent field lattice model, polymer concentration $\bar{\phi}_{P}$ and chain length $N$ (keeping the length ratio of hydrophobic to hydrophilic blocks constant) the effects on temperature-dependent behavior of micelles are studied, in amphiphilic symmetric ABA triblock copolymer solutions. When chain length is increased, at fixed $\bar{\phi}_{P}$, micelles occur at higher temperature. The variations of average volume fraction of stickers $\bar{\phi}_{\mathrm{co}}^{\mathrm{s}}$ and the lattice site numbers $N_{\mathrm{co}}^{\mathrm{ls}}$ at the micellar cores with temperature are dependent on $N$ and $\bar{\phi}_{P}$, which demonstrates that the aggregation of micelles depends on $N$ and $\bar{\phi}_{P}$. Moreover, when $\bar{\phi}_{P}$ is increased, firstly a peak appears on the curve of specific heat $C_{V}$ for unimer-micelle transition, and then in addition a primary peak, the secondary peak, which results from the remicellization, is observed on the curve of $C_{V}$. For a long chain, in intermediate and high concentration regimes, the shape of specific heat peak markedly changes, and the peak tends to be a more broad peak. Finally, the aggregation behavior of micelles is explained by the aggregation way of amphiphilic triblock copolymer. The obtained results are helpful in understanding the micellar aggregation process.
\end{abstract}

Key words: micelle, self-consistent field, amphiphilic copolymer

PACS: $61.25 . H p, 64.75 .+g, 82.60 . F a$

\section{Introduction}

Polymeric micelles constitute a unique class of nanomaterials having a typical core-shell morphology. They are formed from amphiphilic block- or graft-copolymers in a selective solvent, where the nonsoluble parts self-assemble to form the core of the micelles and the soluble parts form the solvated shell. The properties of micelle can be changed by the solution conditions such as concentration, temperature, and chain architecture. Such self-assembly phenomena of amphiphilic molecules are of principal importance in many biological and industrial processes. Recently, self-assembled bolaamphiphile nanotubes have been used as templates to produce metal-coated nanowires [1]. A detailed understanding of the aggregation process is crucial to understand and eventually control their formation for the related applications of micelles.

The triblock copolymers, made up of poly(ethyleneoxide) (PEO) and poly(propyleneoxide) (PPO) blocks, which are experimentally studied as amphiphilic molecules, have been the subject of intense research over the last two decades due to their unique solution behavior [2] 3]. Furthermore, the arrangement of the PPO and PEO blocks in the chain is the key factor affecting self-aggregation and phase behavior of these copolymers, which are well documented in literature [3]. 8 . The temperature induced aggregation behavior of triblock copolymers in aqueous solutions has received great attention during the

\footnotetext{
*xghan0@163.com
} 
recent decades due to their fundamental and practical importance [3, 5, 9]. Compared with experimental studies, however, related theoretical studies are few, especially to account for the effect of chain architecture. Han et al. [10] investigated the effects of the length of each hydrophobic end block and polymer concentration on micellar aggregation in amphiphilic symmetric ABA triblock copolymer solutions. It is found that the broadness of transition is affected by the length of hydrophobic end blocks (i.e., chain length). However, in associative polymers [11], when the total length of hydrophilic blocks is decreased, keeping the chain length constant, the broadness of transition concerned micelles increases. It is an obvious conclusion drawn that the broadness of the transition changes due to the length ratio of hydrophobic to hydrophilic blocks. The chain length is an important parameter to understand the thermodynamics of block copolymers in a selective solvent. In amphiphilic triblock copolymer solutions, however, the effect of chain length on micellar aggregation behavior has not been clarified so far, the length ratio of hydrophobic to hydrophilic blocks remaining constant.

As a mesoscopic polymer theory, the self-consistent field theory (SCFT) has its origin from the field theoretical approach by Edwards [12] and was explicitly adopted to deal with block copolymer structures by Helfand [13]. In recent years, Matsen and Schick proposed a powerful numerical spectral method that could be used to deal with complex microphases [14, 15]. This method is accurate enough but requests a prior knowledge of the symmetry of an ordered structure, which has hindered its application in predicting microphases of complex copolymer structures. Subsequently, Drolet and Fredrickson suggested a new combinatorial screening method [16, 17], which involves a direct implementation of SCFT in real space in an adaptive arbitrary cell. This method proves to be very successful and can be applied to complex copolymer melts. It has also been extended to predict the nanostructures of polymer-grafted nanoparticles [18], which have potential applications in the design and synthesis of hierarchical materials. In addition, SCFT allows us to investigate the aggregate morphology of amphiphilic block copolymers and their blends in a dilute solution [19,-22]. Recently, Matsen extends SCFT to treat diblock copolymers with nongaussian chain of low molecular weight [23].

A lattice model is introduced to self-consistent mean-field theory to treat microphase separation for rod-coil block copolymers [24-26]. In our previous papers [10 11, 27, 28], we have used the SCFT lattice model to study the phase behavior of physically associating polymer solutions. It is found that chain architecture and polymer concentration are important factors which affect the property of temperaturedependent aggregation behavior. Now, in amphiphilic ABA symmetric triblock copolymer solutions, we study chain length and polymer concentration effects on aggregation behavior. It is found that although the length ratio of hydrophobic to hydrophilic blocks remains constant, the increase in the aggregation degree of micelles is also dependent on the chain length, and it is explained by the way of aggregation of amphiphilic triblock copolymer.

\section{Theory}

This section briefly describes the self-consistent field theory (SCFT) lattice model for $n_{P}$ amphiphilic symmetric ABA triblock copolymers which are assumed to be incompressible. Each block molecule consists of $N_{\text {ns }}$ nonsticker segments forming the middle B block and $N_{\text {st }}$ sticker segments forming each end A block, distributed over a lattice. At the same time, $n_{h}$ solvent molecules are placed on the vacant lattice sites. Polymer monomers and solvent molecules have the same size and each occupies one lattice site. The total number of lattice sites is $N_{L}=n_{h}+n_{P} N$. The transfer matrix $\lambda$ is used to describe the polymer chain, which depends only on the chain model used. We assume that

$$
\lambda_{r_{s}-r_{s-1}^{\prime}}^{\alpha_{s-1}}= \begin{cases}0, & \alpha_{s}=\alpha_{s-1} \\ 1 /(z-1), & \text { otherwise }\end{cases}
$$

Here, $r^{\prime}$ denotes the nearest neighboring site of $r . r_{s}$ and $\alpha_{s}$ denote the position and bond orientation of the $s$-th segment of the copolymer, respectively. $\alpha$ can be any of the allowed bond orientations depending on the lattice model used. $z$ is the coordination number of the lattice. This means that the chain is described as a random walk without a possibility of direct backfolding. Although self-intersections of a chain are not permitted, the excluded volume effect is sufficiently taken into account [29]. $G^{\alpha_{s}}(r, s \mid 1)$ is 
the end segment distribution function of the $s$-th segment of the chain. Following the scheme of Schentiens and Leermakers [30], it is evaluated from the following recursive relation:

$$
G^{\alpha_{s}}(r, s \mid 1)=G(r, s) \sum_{r_{s-1}^{\prime}} \sum_{\alpha_{s-1}} \lambda_{r_{s}-r_{s-1}^{\prime}}^{\alpha_{s-1}} G^{\alpha_{s-1}}\left(r^{\prime}, s-1 \mid 1\right)
$$

where $G(r, s)$ is the free segment weighting factor and is expressed as

$$
G(r, s)= \begin{cases}\exp \left[-\omega_{\mathrm{st}}\left(r_{s}\right)\right], & s \in \mathrm{st} \\ \exp \left[-\omega_{\mathrm{ns}}\left(r_{s}\right)\right], & s \in \mathrm{ns}\end{cases}
$$

The initial condition is $G^{\alpha_{1}}(r, 1 \mid 1)=G(r, 1)$ for all the values of $\alpha_{1} \cdot \sum_{r_{s-1}^{\prime}} \sum_{\alpha_{s-1}}$ means the summation over all the possible positions and orientations of the $(s-1)$-th segment of the chain. Another end segment distribution function $G^{\alpha_{s}}(r, s \mid N)$ is evaluated from the following recursive relation:

$$
G^{\alpha_{s}}(r, s \mid N)=G(r, s) \sum_{r_{s+1}^{\prime}} \sum_{\alpha_{s+1}} \lambda_{r_{s+1}^{\prime}-r_{s}}^{\alpha_{s+1}-\alpha_{s}} G^{\alpha_{s+1}}\left(r^{\prime}, s+1 \mid N\right)
$$

with the initial condition $G^{\alpha_{N}}(r, N \mid N)=G(r, N)$ for all the values of $\alpha_{N}$.

In this simulation, the free energy in the canonical ensemble $F$ is defined as

$$
\frac{F\left[\omega_{+}, \omega_{-}\right]}{k_{\mathrm{B}} T}=\sum_{r}\left\{\frac{1}{4 \chi} \omega_{-}^{2}(r)-\omega_{+}(r)\right\}-n_{P} \ln Q_{P}\left[\omega_{\mathrm{st}}, \omega_{\mathrm{ns}}\right]-n_{h} \ln Q_{h}\left[\omega_{h}\right],
$$

where $\chi$ is the Flory-Huggins interaction parameter in the solutions, which equals $\frac{z}{2 k_{\mathrm{B}} T} \epsilon, z$ is the coordination number of the lattice used. $Q_{h}$ is the partition function of a solvent molecule subjected to the field $\omega_{h}(r)=\omega_{+}(r)$, which is defined as $Q_{h}=\frac{1}{n_{h}} \sum_{r} \exp \left[-\omega_{h}(r)\right] . Q_{P}$ is the partition function of a noninteraction polymer chain subjected to the fields $\omega_{\mathrm{st}}(r)=\omega_{+}(r)-\omega_{-}(r)$ and $\omega_{\mathrm{ns}}(r)=\omega_{+}(r)$, which act on sticker and nonsticky segments, respectively. $Q_{P}$ is expressed as $Q_{P}=\frac{1}{N_{L}} \frac{1}{z} \sum_{r_{N}} \sum_{\alpha_{N}} G^{\alpha_{N}}(r, N \mid 1)$, where $r_{N}$ and $\alpha_{N}$ denote the position and orientation of the $N$-th segment of the chain, respectively. $\sum_{r_{N}} \sum_{\alpha_{N}}$ means the summation over all the possible positions and orientations of the $N$-th segment of the chain. Minimization of the free energy function $F$ with $\omega_{-}(r)$ and $\omega_{+}(r)$ leads to the following saddle point equations:

$$
\begin{gathered}
\omega_{-}(r)=2 \chi \phi_{\mathrm{st}}(r), \\
\phi_{\mathrm{st}}(r)+\phi_{\mathrm{ns}}(r)+\phi_{h}(r)=1,
\end{gathered}
$$

where

$$
\phi_{\mathrm{st}}(r)=\frac{1}{N_{L}} \frac{1}{z} \frac{n_{P}}{Q_{P}} \sum_{s \in \mathrm{st}} \sum_{\alpha_{s}} \frac{G^{\alpha_{s}}(r, s \mid 1) G^{\alpha_{s}}(r, s \mid N)}{G(r, s)}
$$

and

$$
\phi_{\mathrm{ns}}(r)=\frac{1}{N_{L}} \frac{1}{z} \frac{n_{P}}{Q_{P}} \sum_{s \in \mathrm{ns}} \sum_{\alpha_{s}} \frac{G^{\alpha_{s}}(r, s \mid 1) G^{\alpha_{s}}(r, s \mid N)}{G(r, s)}
$$

are the average numbers of sticker and nonsticky segments at $r$, respectively, and $\phi_{h}(r)=\left(1 / N_{L}\right)\left(n_{h} / Q_{h}\right)$ $\times \exp \left[-\omega_{h}(r)\right]$ is the average numbers of solvent molecules at $r$.

In our calculations, real space method is implemented to solve the SCFT equations in a cubic lattice with periodic boundary conditions, which is similar to our previous paper [27]. The configuration from SCFT equations is taken as a saddle point configuration. By comparing the free energies of the observed states from different initial fields, a relative stability of the observed morphologies can be obtained.

\section{Result and discussion}

In our studies, the property of symmetric ABA triblock copolymers is characterized by three tunable molecular parameters: $\chi$ (The Flory-Huggins interaction parameter), $N$ (The chain length of copolymer) and $N_{\mathrm{st}} / N_{\mathrm{ns}}$ (the length ratio of each hydrophobic end block to hydrophilic middle block). In this paper, 


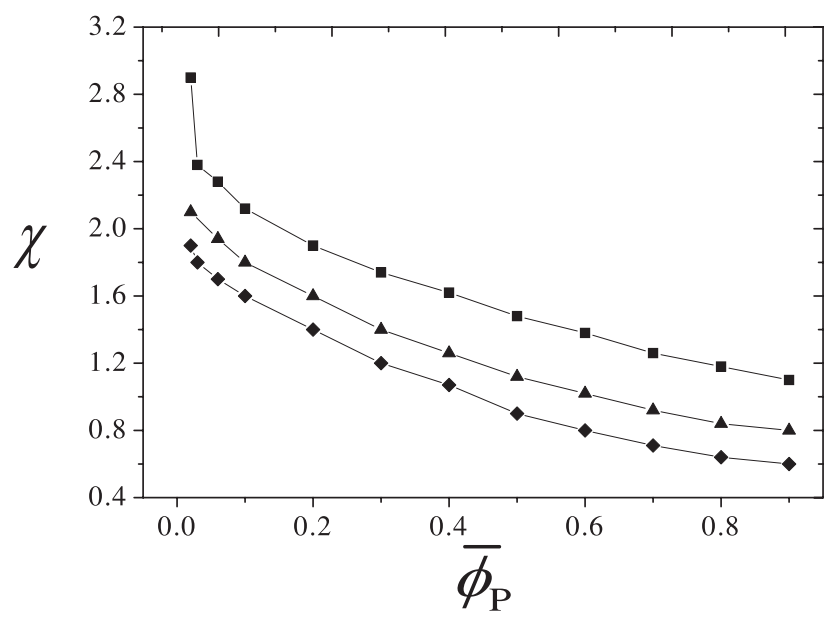

Figure 1. The phase diagram for the amphiphilic symmetric ABA tribolck copolymers with different chain length $N$. The boundary between homogenous solutions and micelle morphology is obtained. The squares, triangles and diamonds correspond to the boundaries for $N=17,26,34$, respectively.

when the chain length is changed, the value of $N_{\mathrm{st}} / N_{\mathrm{ns}}(\simeq 0.23)$ remains constant. The aggregation behavior of micelle morphologies is focused when the length of copolymer is changed. Figure 1 shows the phase diagram of the systems with different chain length $N$. When $\chi$ is increased, the unimer-micelle transition occurs. At fixed $N$, the $\chi$ value on micellar boundary increases with decreasing $\bar{\phi}_{P}$. When $N$ is increased, at fixed $\bar{\phi}_{P}$, the $\chi$ value on micellar boundary shifts to a small value. It is noted that although the length ratio of each hydrophobic end block to hydrophilic middle block remains constant, the increase in the chain length of copolymer is also favorable to the occurrence of micelles in the system.

In order to demonstrate the effects of the chain length $N$ and polymer concentration $\bar{\phi}_{P}$ on aggregation of micelles, the variations of the average volume fraction of stickers $\bar{\phi}_{\mathrm{co}}^{\mathrm{s}}$ and the lattice site numbers $N_{\mathrm{co}}^{\mathrm{ls}}$ at the micellar cores $\left(\phi_{\mathrm{co}}^{\mathrm{s}} \geqslant 0.5\right)$ with $\chi_{r}$ (the $\chi$ deviation from micellar boundary) in various polymer concentrations, for $N=26$ and $N=34$, are presented in figure 2 (a) and figure 4 (a), respectively. For $N=26$, at $\bar{\phi}_{P}=0.1, \bar{\phi}_{\mathrm{co}}^{\mathrm{s}}$, as well as the corresponding $N_{\mathrm{co}}^{\mathrm{ls}}$, smoothly rises with $\chi_{r}$ and then remains constant. When $\chi_{r} \geqslant 0.5, N_{\mathrm{co}}^{\mathrm{ls}}$ does not change with $\chi_{r}$, and the aggregation degree of micelles strengthens from the increase in $\bar{\phi}_{\mathrm{co}}^{\mathrm{s}}$. When $\bar{\phi}_{P}$ is increased the change of $\bar{\phi}_{\mathrm{co}}^{\mathrm{s}}$ with $\chi_{r}$ is not monotonous. At $\bar{\phi}_{P}=0.3$ and $\bar{\phi}_{P}=0.5$, when $\chi_{r}$ is increased, $\bar{\phi}_{\mathrm{co}}^{\mathrm{s}}$ firstly rises, and then a $\bar{\phi}_{\mathrm{co}}^{\mathrm{s}}$-lower region occurs in the range of $\chi_{r}$, and $\bar{\phi}_{\mathrm{co}}^{\mathrm{s}}$ finally tends to be constant. The corresponding $N_{\mathrm{co}}^{\mathrm{ls}}$ firstly rises, and then a jump occurs at the onset of the above lower region. When $\bar{\phi}_{P}=0.8$, $\bar{\phi}_{\mathrm{co}}^{\mathrm{s}}$ always goes up with $\chi_{r}$, going with the slight surge of $N_{\mathrm{co}}^{\mathrm{ls}}$. It is seen that, at intermediate concentrations, when $\chi_{r} \geqslant 1.1$, micelles dissolve and remicellize, which is demonstrated by a decrease of the average volume fraction of stickers at micellar core with increasing from $\chi_{r}=1.3$ to $\chi_{r}=1.4$ (see figure 3 ). This can accelerate the further aggregation of micelles. At high concentrations, the behavior of micellar dissolution and remicellization is restrained. Only a few micelles dissolve to strengthen the aggregation degree of micelles. It is shown that the way of an increase in aggregation degree of micelles depends on polymer concentration. It is noted that when $\chi_{r} \geqslant 0.6, \bar{\phi}_{\mathrm{co}}^{\mathrm{s}}$ at fixed $\chi_{r}$ decreases with an increase in $\bar{\phi}_{P}$ for $N=26$.

For $N=34$ (see figure 4 (a)), when polymer concentration $\left(\bar{\phi}_{P}=0.1\right.$ and 0.3 ) is not high, the tendencies of $\bar{\phi}_{\mathrm{co}}^{\mathrm{s}}$ and $N_{\mathrm{co}}^{\mathrm{ls}}$ to $\chi_{r}$ are similar to those of $N=26$. At intermediate and high polymer concentrations, they are different from those of $N=26$. When $\bar{\phi}_{P}=0.5, \bar{\phi}_{\mathrm{co}}^{\mathrm{s}}$ and $N_{\mathrm{co}}^{\mathrm{ls}}$ always smoothly increase with $\chi_{r}$. At $\bar{\phi}_{P}=0.8, \bar{\phi}_{\text {co }}^{\text {s }}$ always smoothly increase with $\chi_{r}$, but $N_{\text {co }}^{\mathrm{ls}}$ goes down slowly with $\chi_{r}$. It is demonstrated that micelles almost do not dissolve at $\bar{\phi}_{P}=0.5$. Consequently, the micellar further aggregation is restrained in a way near the micellar boundary. $\bar{\phi}_{\mathrm{co}}^{\mathrm{s}}$ at $\bar{\phi}_{P}=0.5$ is larger than that of $\bar{\phi}_{P}=0.8$ until $\chi_{r} \geqslant 1.5$, which is larger from the case of $N=26$. It is demonstrated that, at intermediate and high concentrations, the further aggregation of micelles is markedly affected by the increase in $N$.

The heat capacity is an important thermodynamic signature to test the occurrence of a phase transition in a system. The shape of specific heat peak may also be a characteristic of transition. [11, 31]. In 

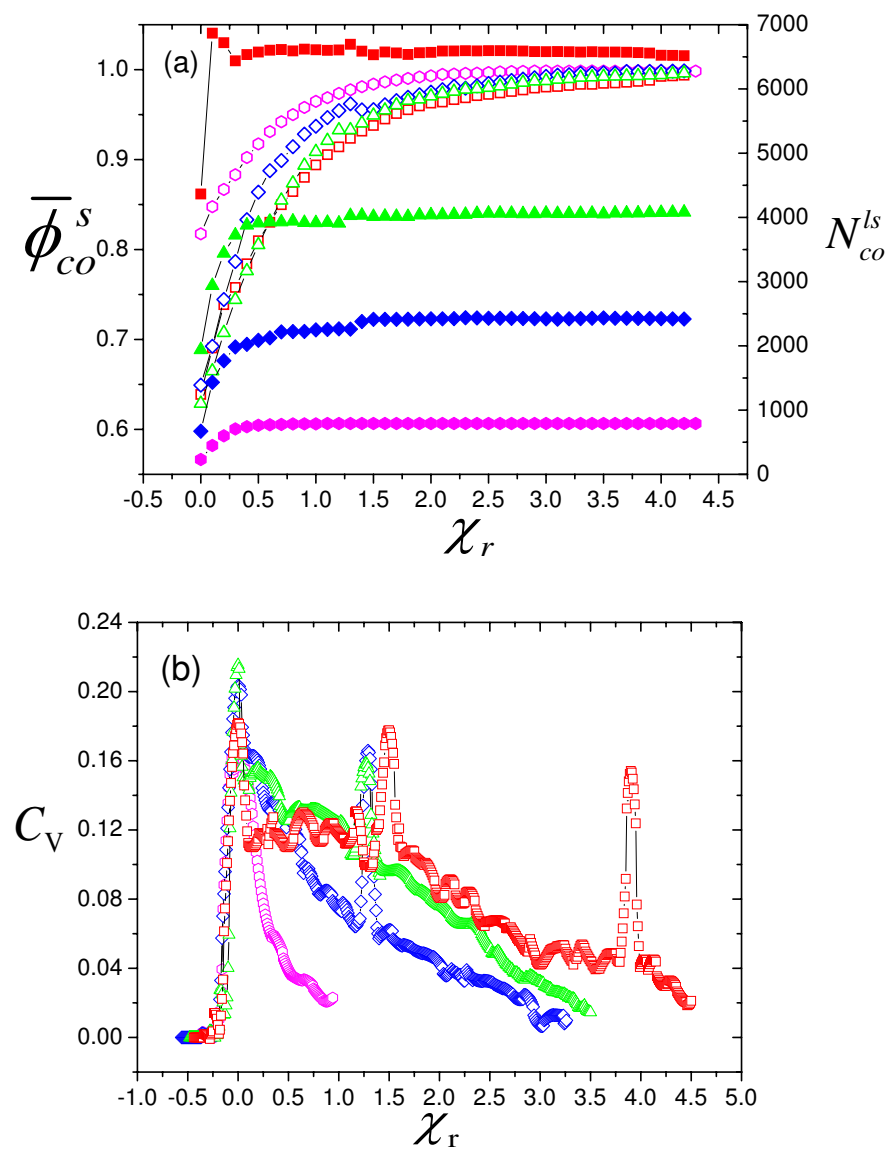

Figure 2. (Color online) The variations of average volume fractions of stickers $\bar{\phi}_{\text {st }}$ and lattice site numbers $N_{\mathrm{co}}^{\mathrm{ls}}$ at the micellar cores in different amphiphilic ABA tribolck copolymers with the $\chi$ deviation from micellar boundary $\chi_{r}$, for various $\bar{\phi}_{P}$ at $N=26$ is presented in figure 2 (a). The open and solid, open and solid triangles, open and solid diamonds, and open and solid hexagons denote the $\bar{\phi}_{\text {st }}$ and $N_{\text {co }}^{\mathrm{ls}}$ for $\bar{\phi}_{P}=0.8,0.5,0.3,0.1$, respectively; The changes of heat capacity for different $\bar{\phi}_{P}$ in figure 2 (a) with $\chi_{r}$ are shown in figure 2 (b). The squares, triangles, diamonds and hexagons denote the case of $\bar{\phi}_{P}=0.8,0.5,0.3,0.1$, respectively.

this work, the heat capacity per site of amphiphilic symmetric ABA triblock copolymers is expressed as (in the unit of $k_{\mathrm{B}}$ ):

$$
C_{V}=\left(\frac{\partial U}{\partial T}\right)_{N_{L}, n_{P}}=\frac{1}{N_{L}} \chi^{2} \frac{\partial}{\partial \chi}\left(\sum_{r} \phi_{\mathrm{st}}^{2}(r)\right) .
$$

The $C_{V}\left(\chi_{r}\right)$ curves for the unimer-micelle transition in various $\bar{\phi}_{P}$ at $N=26$ and $N=34$ are shown in figure 2(b) and figure 4 (b), respectively. For unimer-micelle transition, an asymmetric specific heat peak appears. For $N=26$, when $\bar{\phi}_{P}=0.1$, there is only a peak on $C_{V}\left(\chi_{r}\right)$ curves. when $\bar{\phi}_{P}$ is increased, a primary and a secondary peaks, are observed as shown in figure 2 (at intermediate and high concentrations). When $\bar{\phi}_{P}=0.3$ and 0.5 , the primary peak is higher than the corresponding secondary peak. When $\bar{\phi}_{P}=0.8$, a primary and two secondary peaks occur, and one of them is nearly as high as the primary peak. The primary and secondary peaks tend to be similar. The occurrence of the secondary peak is according to the saltation of the $\chi_{r}$ curves of the average volume fraction of stickers $\bar{\phi}_{\text {co }}^{\text {s }}$ and the lattice site numbers $N_{\mathrm{co}}^{\mathrm{ls}}$ at the micellar cores. Ignoring the secondary peak, the specific heat peak becomes broad with increasing $\bar{\phi}_{P}$. For $N=34$, when polymer concentration is low, the peak is narrow and similar to the 


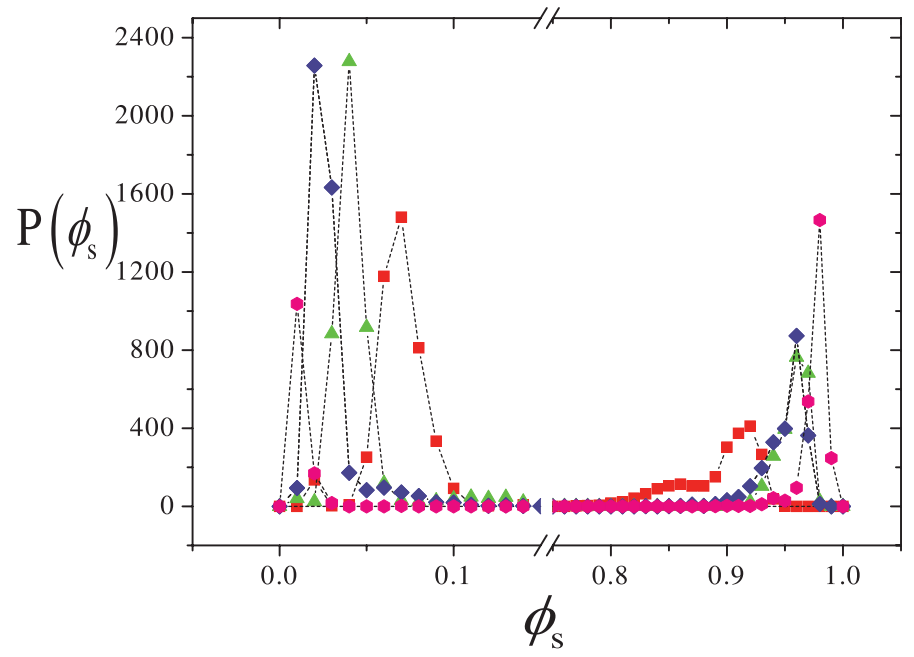

Figure 3. (Color online) The distributions of the numbers of micellar core sites with $\phi_{\mathrm{co}}^{\mathrm{s}}$ at $\bar{\phi}_{P}=0.3$ and $N=26$. The squares, triangles, diamonds and pentacles correspond to $\chi_{r}=0.7,1.3,1.4,2.4$, respectively.

corresponding case of $N=26$. When $\bar{\phi}_{P}$ is increased, the peak shape changes and the peak also becomes broad. With increasing $\bar{\phi}_{P}$, the maximum of $C_{V}$ shifts to a big $\chi_{r}$ and the curves of $C_{V}\left(\chi_{r}\right)$ tend to be not smooth, thus the broad peak seems to be a primary peak. For a long chain, the peak shape changes markedly at intermediate and high concentrations.

When temperature drops to a certain extent, micelles appear, and with a further decrease in temperature the aggregation degree of micellar cores markedly strengthens. It is indicated above that the temperature-dependent aggregation behavior of micelles depends on polymer concentration and the chain length. The micellization of hydrophobic end blocks of triblock copolymer can be considered in the following ways. One is that both end blocks of each individual molecule could be incorporated into the same core, the other is that the two hydrophobic ends of triblock copolymer could be incorporated into two adjacent micelles. For a short chain, at low concentration, the first micellization way is dominant. When polymer concentration is increased, the possibility of the two hydrophobic ends of triblock copolymer to be incorporated into two adjacent micelles will rise markedly. At the same time, the aggregation degree of micelles on micellar boundary tends to decrease. Therefore, at intermediate concentrations, the further micellization of triblock copolymers is delayed for a while due to the correlations from chain connection among micelles. When temperature is decreased to some extent, many micelles will be dissolved, and then remicellize. On remicellization, the distribution width of the volume fraction of stickers at micellar cores increases which is different from the general variation of distribution for volume fraction of stickers at micellar cores with $\chi_{r}$. At the same time, the relationship among the micelles becomes stronger, as shown in figure 5. At high concentrations, the correlations among micelles strengthens compared with intermediate concentrations, only a few micelles dissolve and some new micelles form, which is demonstrated by keeping the tendency of $\bar{\phi}_{\text {st }}\left(\chi_{r}\right)$ to increase and the surge of $N_{l s}\left(\chi_{r}\right)$ with $\chi_{r}$. For a long chain, when concentration is low, the case is similar to that of a short chain. When the polymer concentration is increased, the chain length effect emerges. The two hydrophobic ends of triblock copolymer will be almost absolutely incorporated into two adjacent micelles or small aggregates $\left(\phi_{\mathrm{co}}^{\mathrm{s}}<0.5\right.$ in figure 3). When $\bar{\phi}_{P}=0.5$, quite a few small aggregates form. The increase in aggregation degree of micelles is caused by dissolution of small aggregates, and thus the corresponding $N_{\mathrm{co}}^{\mathrm{ls}}$ does not surge. At high concentrations, micelles form easily, and the quantity of small aggregates decreases notably. Thus, the further aggregation of micelles results from the dissolution of a few micelles. In summary, at intermediate concentrations for a short chain, the increase in aggregation degree of micelles is by its dissolution and remicellization. When polymer concentration or chain length is increased, the way of dissolution and remicellization is restrained, and thus the temperature-dependent aggregation behavior of micelles is changed.

In the end of paper, the validity of self-consistent field theory for the above results should be illuminated. Capture can be an essential feature for the accounted effect of polymer concentration $\bar{\phi}_{P}$ and 

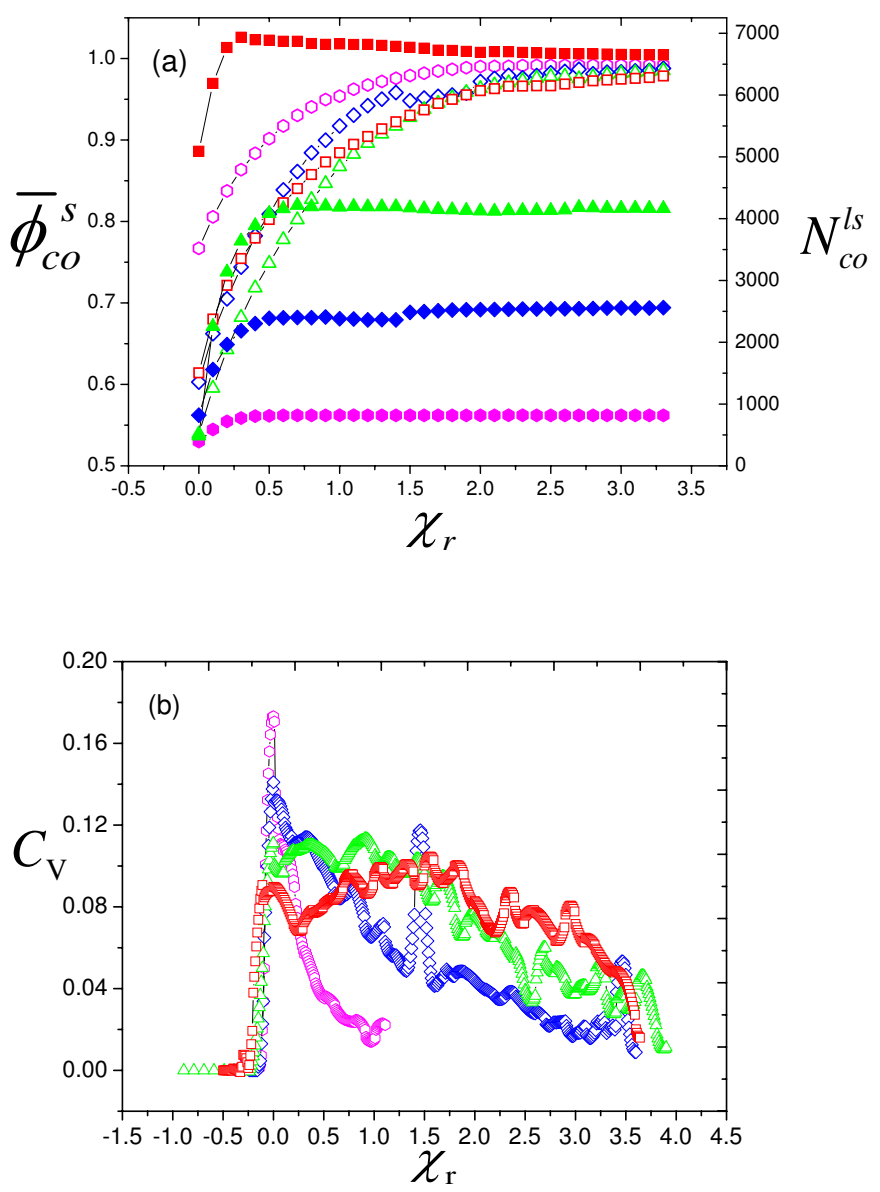

Figure 4. (Color online) The variations of the average volume fractions of stickers $\bar{\phi}_{\text {st }}$ and lattice site numbers $N_{\text {co }}^{\text {ls }}$ at the micellar cores in different amphiphilic symmetric ABA tribolck copolymers with the $\chi$ deviation from micellar boundary $\chi_{r}$, for various $\bar{\phi}_{P}$ at $N=34$ is presented in figure 4 (a). The open and solid squares, open and solid triangles, open and solid diamonds, and open and solid hexagons denote the $\bar{\phi}_{\text {st }}$ and $N_{\text {co }}^{\text {ls }}$ for $\bar{\phi}_{P}=0.8,0.5,0.3,0.1$, respectively; The changes of heat capacity for different $\bar{\phi}_{P}$ in figure 4 (a) with $\chi_{r}$ is shown in figure 4 (b). The squares, triangles, diamonds and hexagons denote the case of $\bar{\phi}_{P}=0.8,0.5,0.3,0.1$, respectively.

chain length $N$. The chain accounted in the work should belong to gaussian chain. Using a self-consistent field lattice model, the phase diagram of coil-coil diblock copolymers for $N=20$ in the three dimension space [24] is consistent with the Matsen-Schick phase diagram. [14], and the results for the solution of homopolymer length $N=30$ in a two dimensional square lattice is also in reasonable agreement with the theoretical prediction [27]. Furthermore, the effect of relative chain length is also accounted for polymer blends [15]. The above effects from chain length $N=26$ and $N=34$ should be reasonable. SCFT is extensively applied to the study of the phase behavior of dilute amphiphilic block copolymer solutions, and the obtained results at $\bar{\phi}_{P}=0.1$ have been proved by experimental observations [22]. The specific heat peak for the transition concerned with micelles is also calculated in physically associating polymer solutions [27], and the effect of concentration on specific heat peak (not shown) is in reasonable agreement with that of the related system [32]. Therefore, the concentration effect accounted for in the work by self-consistent field theory is reasonably qualitative. 


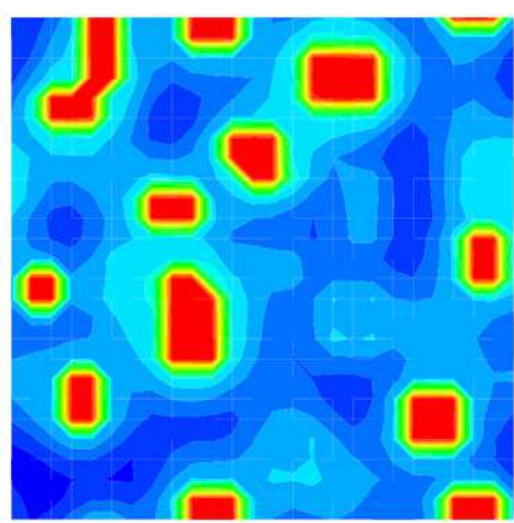

(a)

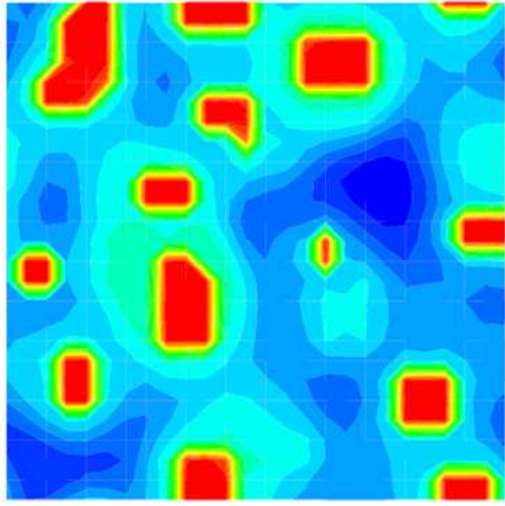

(b)

Figure 5. (Color online) The cross sections of the system are presented in figure 5 Figure 5 (a) and (b), which demonstrate the changes concerned with remicelliztion, correspond to the cases of $\chi_{r}=1.3$ and $\chi_{r}=1.4$, respectively, for $\bar{\phi}_{P}=0.3$ and $N=26$.

\section{Conclusion and summary}

Using the self-consistent field lattice model, polymer concentration $\bar{\phi}_{P}$ and the chain length $N$ (the length ratio of hydrophobic to hydrophilic blocks remains constant), the effects on the aggregation behavior of micelles are studied in amphiphilic symmetric ABA triblock copolymer solutions. When $N$ is increased, at fixed $\bar{\phi}_{P}$, micelles occur at a higher temperature. The variations of the average volume fraction of stickers $\bar{\phi}_{\mathrm{co}}^{\mathrm{s}}$ and the lattice site numbers $N_{\mathrm{co}}^{\mathrm{ls}}$ at the micellar cores with temperature depend on $N$ and $\bar{\phi}_{P}$, which is demonstrated by the change of the specific heat peak. For a short chain, when $\bar{\phi}_{P}$ is increased, firstly a peak appears on the curve of $C_{V}$ for the micellar appearance, and then, in addition to a primary peak, the secondary peak is observed. For a long chain, in intermediate and high concentration regimes, the shape of a specific heat peak changes markedly, and it tends to a broader primary peak, which is explained by the aggregation way of amphiphilic triblock copolymer. For a short chain, at intermediate concentrations, the way of two hydrophobic ends of triblock copolymer to be incorporated into two adjacent micelles is dominant. Therefore, the aggregation degree of the micelles increases by its dissolution and remicellization. When polymer concentration or chain length is increased, the way of dissolution and remicellization is restrained, and thus the temperature-dependent aggregation behavior of the micelles changes.

\section{Acknowledgements}

This research is financially supported by the National Nature Science Foundations of China (11147132) and the Inner Mongolia municipality (2012MS0112), and the Innovative Foundation of Inner Mongolia University of Science and Technology (2011NCL018).

\section{References}

1. Matsui H., Pan S., Gologan B., Jonas S.H., J. Phys. Chem. B, 2000, 104, 9576; doi 10.1021/jp000762g

2. Riess G., Prog. Polym. Sci., 2003, 28, 1107; doi 10.1016/S0079-6700(03)00015-7

3. Trong L.C., Djabourov M., Ponton A., J. Colloid Interface Sci., 2008, 328, 278; doi 10.1016/j.jcis.2008.09.029

4. Zhou Z., Chu B., Macromolecules, 1994, 27, 2025; doi 10.1021/ma00086a008

5. Chu B., Langmuir, 1996, 11, 414; doi 10.1021/la00002a009

6. Wu J., Xu Y., Dabros T., Hamza H., Colloids Surf. A: Physicochem. Eng. Asp., 2005, 252, 79; doi $10.1016 /$ j.colsurfa.2004.09.034 
7. Errico G.D., Paduan L., Khan A., J. Colloid Interface Sci., 2004, 279, 379; doi 10.1016/j.jcis.2004.06.063

8. Patel T., Bahadur P., Mata J., J. Colloid Interface Sci., 2010, 345, 346, doi 10.1016/j.jcis.2010.01.079

9. Hugouvieux V., Axelos M.A.V., Kol M., Soft Matter, 2011, 7, 2580; doi 10.1039/C0SM01018A.

10. Han X.G., Ma Y.H., Ouyang S.L., Condens. Matter Phys., 2013, 16, 33601; doi 10.5488/CMP.16.33601

11. Han X.G., Zhang X.F., Ma Y.H., Condens. Matter Phys., 2012, 15, 3, 33602; doi 10.5488/CMP.15.33602

12. Edwards S.F., Proc. Phys. Soc. London, 1965, 85, 613; doi $10.1088 / 0370-1328 / 85 / 4 / 301$

13. Helfand E., J. Chem. Phys., 1975, 62, 999; doi 10.1063/1.430517

14. Matsen M.W., Schick M., Phys. Rev. Lett., 1994, 72, 2660; doi org/10.1103

15. Matsen M.W., Macromolecules, 1995, 28, 5765; doi 10.1021/ma00121a011

16. Drolet F., Fredrickson G.H., Phys. Rev. Lett., 1999, 83, 4317; doi 10.1103/PhysRevLett.83.4317

17. Drolet F., Fredrickson G.H., Macromolecules, 2001, 34, 5317; doi 10.1021/ma0100753.

18. Reister E., Fredrickson G.H., J. Chem. Phys., 2005, 123, 214903; doi $/ 10.1063 / 1.2117008$

19. He X., Liang H., Huang L., Pan C., J. Phys. Chem. B, 2004, 108, No. 5, 1731; doi 10.1021/jp0359337

20. Jiang Y., Chen T., Ye F., Liang H., Shi A.-C., Macromolecules, 2005, 38, 6710; doi 10.1021/ma050424j

21. Wang R., Tang P., Qiu F., Yang Y., J. Phys. Chem. B, 2005, 109, 17120; doi 10.1021/jp053248p

22. Wang L.Q., Lin J.P., Soft Matter, 2011, 7, 3383; doi 10.1039/C0SM01079K.

23. Matsen M.W., Macromolecules, 2012, 45, 8502; doi 10.1021/ma301788q

24. Chen J.Z., Zhang C.X., Sun Z.Y., Zheng Y.S., An L.J., J. Chem. Phys., 2006, 124, 104907; doi 10.1063/1.2176619.

25. Chen J.Z., Sun Z.Y., Zhang C.X., An L.J., Tong Z., J. Chem. Phys., 2007, 127, 024105; doi 10.1063/1.2750337.

26. Chen J.Z., Sun Z.Y., Zhang C.X., An L.J., Tong Z., J. Chem. Phys., 2008, 128, 074904; doi 10.1063/1.2831802

27. Han X.G., Zhang C.X., J. Chem. Phys., 2010, 132, 164905; doi 10.1063/1.3400648

28. Han X.G., Zhang X.F., Ma Y.H., Zhang C.X., Guan Y.B., Condens. Matter Phys., 2011, 14, 43601; doi $10.5488 / C M P .14 .43601$

29. Medvedevskikh Y.G., Condens. Matter Phys., 2001, 4, 209; doi 10.5488/CMP.4.2.209

30. Leermakers F.A.M., Scheutjens J.M.H.M., J. Chem. Phys., 1988, 89, 3264; doi 10.1063/1.454931

31. Douglas J.F., Dudowicz J., Freed K.F., J. Chem. Phys., 2006, 125, 114907; doi 10.1063/1.2356863

32. Dudowicz J., Freed K.F., Douglas J.F., J. Chem. Phys., 1999, 111, 7116; doi 10.1063/1.480004 


\title{
Самоузгоджене теоретико-польове моделювання амфіфільних триблочних кополімерних розчинів: ефекти концентрації та довжини ланцюга полімерів
}

\author{
К.-Г. Ган, Й.-Г. Ма
}

Університет науки і технологій Внутрішньої Монголії, Баоту 014010, Китай

Використовуючи самоузгоджену польову ґраткову модель, вивчаються ефекти концентрації $\bar{\phi}_{P}$ і довжини ланцюга $N$ полімера (при фіксованому відношенні довжин гідрофобних і гідрофільних блоків) на температуро-залежну поведінку міцел в амфіфільних симетричних АВА триблочних кополімерних розчинах. Якщо довжина ланцюга зростає, при фіксованому $\bar{\phi}_{P}$, міцели утворюються при вищій температурі. Зміна середньої об'ємної долі стикерів $\bar{\phi}_{\text {со }}^{\text {s }}$ та числа вузлів ґратки $N_{\text {co }}^{\mathrm{ls}}$ з температурою при міцелярних корах залежать від $N$ і $\bar{\phi}_{P}$, що вказує на залежність агрегації міцел від $N$ і $\bar{\phi}_{P}$. Крім того, якщо $\bar{\phi}_{P}$ зростає, спочатку пік виникає на кривій питомої теплоємності $C_{V}$ для переходу мономер-міцела, і потім додатково спостарігаються на кривій $C_{V}$ основний пік, вторинний пік, які $\epsilon$ результатом реміцелізації. Для довгого ланцюга при режимах проміжних і високих концентрацій значно змінюється форма піку питомої теплоємності, і пік прямує до ширшого піку. Накінець, агрегаційна поведінка міцел пояснюється способом агрегації амфіфільного триблочного кополімера. Отримані результати є корисними для розуміння процесу агрегації міцел.

Ключові слова: міцела, самоузгоджене поле, амфіфільний кополімер 